\title{
Determination of Harmful Trace Impurities in Salt or Brine for Sodium Chloride Electrolysis with Mercury Cathode by Spectrochemical Addition Method, and Sampling Study*
}

\author{
Nakaaki ODA** and Sadayuki TsunOo**
}

(i) The spectrochmical method previously reported $^{1)}$ can be applied to salt or brine for sodium chloride electrolysis with mercury cathode, if such harmful impurities as, $\mathrm{Cr}, \mathrm{Mn}, \mathrm{Mo}, \mathrm{Ni}$, Ti and V present more than $10^{-3} \sim 10^{-4} \%$ to $\mathrm{NaCl}$ in sample materials, with $8 \%$ of variation coeffecient. However, this analytical errors increase when those impurities present less than $10^{-3} \sim 10^{-4} \%$. A source of error in analyses of $10^{-4} \sim 10^{-5} \%$ impurities arises from the fact that the line intensity due to those impurities are not sufficient for accurate microphotometry.

(ii) In previous reports, ${ }^{3}$ ) the authors described the spectrochemical addition method, ${ }^{4}$ which can analyse trace impurities $\left(10^{-5} \%\right)$ in zinc. This report gives a routine method for the analysis of harmful trace impurities $\left(10^{-4} \sim 10^{-5} \%\right.$; as optical density, $\log \left(J_{B} / J_{B^{\prime}}\right)=0.2-0.0$, named "A" range.) in salt and brine by the spectrochemical addition method.

The photometric intensity ratio, which was derived in our previous study is used and is defined as follows;

$$
k x=\left(J_{1} / J_{B^{\prime}}\right)-\left(J_{1} / J_{B}\right)
$$

Where $x=$ impurity per cent to be analized,

$J_{1}=$ photometric galvanometer deflection of internal standard line in "A" range,

$J_{B}{ }^{\prime}=$ photometric galvanometer deflection of impurity line and background radiation in "A" range,

$J_{B}=$ photometric galvanometer deflection of background radiation near the impurity line in "A"

range,

$k=$ constant, experimentally determined.

(iii) An impurity element to be determined (Mo) is added to the sample solution, in such amount as a $\%, 2$ a $\%, 3$ a $\% \cdots \cdots$ and so on. Thus the sample solution series should have $(a+x) \%,(2 a+x) \%$, $(3 a+x) \% \cdots \cdots$ and so on (Mo). Plot are made of \% element added (Mo) vs photometic intensity ratio (1) using ordinary co-ordinates (Fig. 1). All points should fall on a straight line, if the intensity of all spectral lines are present in "A" range. The intercept of this extrapolation with the abscissa gives the concentration $(x \%)$ of the element to be determined in the sample solution.

The standard deviation in this analytical value, calculated from $n$-steps addition (as $n$-repeats) is

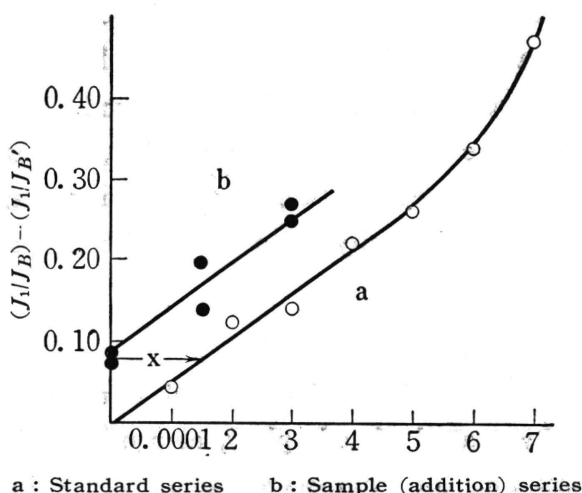

Fig. 1 An example of the curve of addition

\footnotetext{
* Application of Quantitative Spectrochemical Analysis to NaCl Electrolytic Industry (Part 2)

** Takaoka Factory, Nippon Soda Kogyo Co., Ltd., Takaoka, Toyama

The original written in Japanese can be seen in J. Electrochem. Soc. Japan 28, 514 (1960).
} 
Table 1 Analytical Sensitivity and Error of This Spectrochemical Addition Method

\begin{tabular}{|c|c|c|c|c|c|c|c|c|}
\hline \multirow{2}{*}{\multicolumn{2}{|c|}{$\begin{array}{l}\text { Impurity } \\
\text { element wave } \\
\text { length in } \AA\end{array}$}} & \multicolumn{3}{|c|}{ Upper limit of "A" range } & \multicolumn{4}{|c|}{ Standard deviation of average from $n$ repeated analyses } \\
\hline & & $\%$ & $J_{B} / J_{B}$ & $J_{0} / J_{B}^{*}$ & $n=1$ & $n=3$ & $n=6$ & $n=9$ \\
\hline $\mathrm{Cr} I$ & 3605.33 & 0.0005 & 1.35 & 2.50 & 0.000039 & 0.000023 & 0.000016 & 0.000013 \\
\hline Mn & 2798.27 & 0.0002 & 1.57 & 1.03 & 0.000011 & 0.000006 & 0.000005 & 0.000004 \\
\hline Mo & 3170.35 & 0.0003 & 1.34 & 1.24 & 0.000013 & 0.000008 & 0.000005 & 0.000004 \\
\hline $\mathrm{Ni} I$ & 3414.77 & 0.0007 & 1.13 & 1.41 & 0.000025 & 0.000014 & 0.000010 & 0.000008 \\
\hline Ti II & 3349.04 & 0.0005 & 1.21 & 1.49 & 0.000020 & 0.000012 & 0.000008 & 0.000007 \\
\hline V I & 3183.91 & 0.0005 & 1.35 & 1.26 & 0.000017 & 0.000010 & 0.000007 & 0.000006 \\
\hline
\end{tabular}

${ }^{*} J_{0} / J_{B}$ shows the level of background radiation on this analytical condition.

Table 2 An Example of Calculation in This Spectrochemical Addition Method (Mn in salt solutions $\mathrm{A} \sim \mathrm{D}$ from one lot of salt sample)

\begin{tabular}{|c|c|c|c|c|c|c|}
\hline \multirow{2}{*}{$\begin{array}{c}\text { Mn addition } \\
(\%)\end{array}$} & \multicolumn{4}{|c|}{ Photometric intensity ratio $(1)(\times 100)$} & \multirow{2}{*}{ Sum } & \multirow{2}{*}{ Mean } \\
\hline & A & B & C & $\mathrm{D}$ & & \\
\hline 0.0002 & $\begin{array}{ll}48 & 5 \\
53 & \end{array}$ & $\begin{array}{ll}51 & 18 \\
69\end{array}$ & $\begin{array}{ll}58 & \\
59 & 1\end{array}$ & $\begin{array}{ll}58 & 3 \\
61 & 3\end{array}$ & 457 & 57.1 \\
\hline 0.0001 & $\begin{array}{ll}30 & 3 \\
33 & 3\end{array}$ & $\begin{array}{ll}41 & 3 \\
38 & 3\end{array}$ & $\begin{array}{ll}31 & 2 \\
33 & 2\end{array}$ & $\begin{array}{ll}37 & \\
25 & 12\end{array}$ & 268 & 34.5 \\
\hline 0.0000 & $\begin{array}{ll}11 & 1 \\
12 & 1\end{array}$ & $\begin{array}{ll}20 & \\
18 & 2\end{array}$ & $\begin{array}{l}26 \\
22\end{array} \quad 4$ & $\begin{array}{ll}13 & 3 \\
10 & \end{array}$ & 132 & 16.5 \\
\hline Sum & 187 & 237 & 229 & 204 & 857 & \\
\hline $\begin{array}{c}\text { Average } \Delta \\
\text { diff. to } \Delta \\
\text { Mn } \%\end{array}$ & $\begin{array}{c}31.2 \\
10.9 \\
0.00005_{4}\end{array}$ & $\begin{array}{c}39.5 \\
19.2 \\
0.00009_{5}\end{array}$ & $\begin{array}{c}38.2 \\
17.9 \\
0.00008_{8}\end{array}$ & $\begin{array}{c}34.0 \\
13.7 \\
0.00006_{8}\end{array}$ & & \\
\hline
\end{tabular}

Difference of photometric intensity ratio, corresponding to one step addition $\%$ $(0.0001 \%)=(57.1-16.5) / 2=20.3=\Delta$

Estimation of standard deviation from the average range of twelve 2 repeated determination ${ }^{6)} \quad(C=1.16, \phi=11)$.

Standard deviation of single determination.

photometric intensity ratio, $\boldsymbol{R} / C=4.8 ! 1.6=4.1$

$\%$ of impurity $(0.0001 / 20.3) \times 4.1=0.000020 \%$

Standard deviation of analytical results (as average of 6 repeated determination).

$0.000020 / \sqrt{6}=0.00000082 \%$.

Italics show differences $(R)$ of 2 repeated photometric intensity ratio $(\times 100)$.

equal to the corresponding error in a single observation divided by $\sqrt{n}{ }^{2), 5}$. Thus, the larger the number of observation, the smaller the standard deviation (the smaller analytical error) should be expected. Expected standard deviations at various $n$, upper limits of impurities concentrations and then photometric intensity ratios (1) are shown in Table 1 . From these results, the authors decided that $n=6$ ( 3 steps $\times 2$ repeats) for this spectrochemical addition method.

Besides of the calculation procedure of impurity concentration, excitation condition and photographic procedure are identical to the previous report. Table 2 shows an example of calculation procedure of impurity \% ( $\mathrm{Mn}$ ) from photometric intensity ratio (1), without plotting spectrochemical addition curves.

\section{Sampling Study}

(i) Sampling problems, concerning the application of our previously described spectrochemical method, for operation and quality control of soda plant, as routine industrial analysis were studied.

(ii) Procedure of nested sampling (or multi-stage sampling) ${ }^{6), 7)}$ in statistical experimental design have been used to study the variation of various operations in this analytical method. Three stages and their repeats are shown in Fig. 2. The variation analysis of various operation in this analytical method, carried out for $\mathrm{Cr}, \mathrm{Mn}, \mathrm{Ti}$ and $\mathrm{V}$ in insoluble matter of salt are shown in Table 3. It has been 
possible to decide in this way the amount of salt for sample preparation of this method.

(iii) Sampling procedure, concluded from the results obtained, practical consideration, man-hours, and cost is as follows. Five $0.5 \mathrm{Kg}$ salt sample took by sampling-thief (vinyl products) from four corners and center of 8-ton freight track are a collection of primary sampling unit. Fifteen primary samples are mixed (about $38 \mathrm{Kg}$ ), and are quartered six times. Resulting 200 300 g sample salt are used for analysis of harmful impurities by this spectrochemical method, as the representing sample of 120 tons bulk salt.

Also, an example of this analytical method carried out for insoluble matter of India salt are shown in Fig. 3.

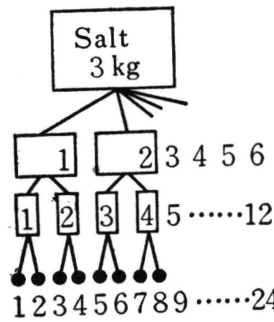

Operational Stage

Sampling for analysis

(A) 6 repeats

Preparation of solution

(B) 2 repeats

Spectrochem. analysis

24

(E) 2 repeats

Fig. 2 Experimental design for variance analysis of variance operational stage

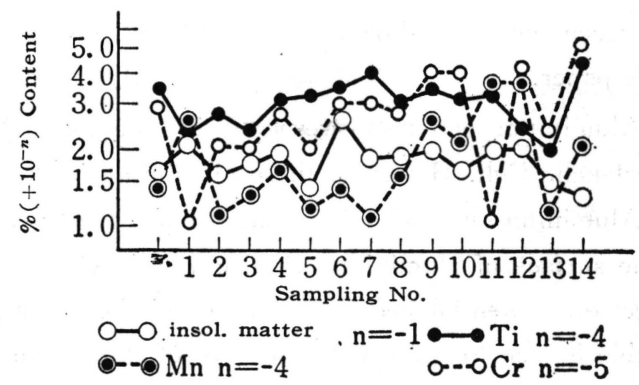

Fig. 3 An example of sampling and analytical results of this method.

(Sample : Insoluble matter of India salt)

Table 3 Variance Analysis of Various Operation Stages in This Spectrochemical Analysis

\begin{tabular}{|c|c|c|c|c|c|c|}
\hline \multirow{2}{*}{ Stage } & \multicolumn{4}{|c|}{ Mean square $\left(\times 10^{-11}\right)$} & \multirow{2}{*}{$\begin{array}{c}\text { Degree } \\
\text { of } \\
\text { freedom }\end{array}$} & \multirow{2}{*}{$\begin{array}{l}\text { Expected value of } \\
\text { mean square }\end{array}$} \\
\hline & $\mathrm{Cr}$ & $\mathrm{Mn}$ & $\mathrm{Ti}$ & $\mathbf{v}$ & & \\
\hline A. Sampling $(50 \mathrm{~g})$ & $186^{* *}$ & $1188^{* *}$ & 92.6 & 10.4 & 5 & $\sigma^{2} E+2 \sigma^{2} B(A)+4 \sigma^{2} A$ \\
\hline B. Prepn. of soln. & 2.7 & 25 & 70.5 & 3.5 & 6 & $\sigma^{2} E+2 \sigma^{2} B(A)$ \\
\hline E. Spect. anal. & 2.2 & 22.7 & 55.0 & 6.0 & 12 & $\sigma^{2} E$ \\
\hline Mean. of imp. $\%$ & 0.00008 & 0.00051 & 0.0031 & 0.00006 & & \\
\hline
\end{tabular}

** very significant by F-test.

(Received Nov. 20, 1959)

\section{Literature :}

1) N. Oda, S. Tsunoo, K. Tsukashima, This Journal 28, E-164 (1960).

2) J. Mandel, Ind. Eng. Chem. Anal. Ed. 18, 280 (1946).

3) N. Oda, S. Tsunoo, T. Hashimoto, J. Japan Inst. Metals 23, 86 (1959); N. Oda, S. Tsunoo, ibid. 24, 146 (1960).

4) L. H. Ahrens, “Spectrochemical Analysis,” pp. 135 (1950)., Addison Wesley Press. Inc.; A. Mayer,W. J. Rrice, "Chemical and Spectrographic Analysis of Magnesium and Its Alloys”, pp. 5316(1954), Magnesium Elektron Ltd., Manchester; J. K. Hurwitz, Anal. Chem. 25, 1028(1953).

5) S. Ramawamy, M. Padmanbham, Chem. Age India, 1, 51 (1956).

6) M. Masuyama, “Experimental Design” pp. 37, 67 (1956), Iwanami Book Co.; Nippon Kagaku Gijutsu Renmei, "Statistical Table A.", Chap. 30, p. 30; K. Ishikawa, "Sampling in Industry" p. 27, 131, Tokyo (1952)., Maruzen Book Co.

7) R. H. Mathis, Anal. Chem. 29, 1046 (1957); G. Wernimont, ibid. 23, 1572 (1951). 